\title{
Correction to: Small area estimation with mixed models: a review
}

\author{
Shonosuke Sugasawa ${ }^{1} \cdot$ Tatsuya Kubokawa $^{2}$ \\ Published online: 16 February 2021 \\ (c) Japanese Federation of Statistical Science Associations 2021
}

\section{Correction to: Japanese Journal of Statistics and Data Science https://doi.org/10.1007/s42081-020-00076-x}

The article "Small area estimation with mixed models: a review", written by Shonosuke Sugasawa and Tatsuya Kubokawa, was originally published Online First without Open Access. After publication in volume 3, issue 2, page 693-720 the author decided to opt for Open Choice and to make the article an Open Access publication. Therefore, the copyright of the article has been changed to (C) The Author(s) 2020 and the article is forthwith distributed under the terms of the Creative Commons Attribution 4.0 International License (https://creativecommons.org/licenses/by/4.0/), which permits use, sharing, adaptation, distribution and reproduction in any medium or format, as long as you give appropriate credit to the original author(s) and the source, provide a link to the Creative Commons licence, and indicate if changes were made. The original article has been corrected.

Publisher's Note Springer Nature remains neutral with regard to jurisdictional claims in published maps and institutional affiliations.

The original article can be found online at https://doi.org/10.1007/s42081-020-00076-x.

Tatsuya Kubokawa

tatsuya@e.u-tokyo.ac.jp

1 Center for Spatial Information Science, The University of Tokyo, Tokyo, Japan

2 Faculty of Economics, The University of Tokyo, 7-3-1 Hongo, Bunkyo-ku, Tokyo 113-0033, Japan 